\title{
Sling tray mechanical anti-swing system simulation and modeling of ship-mounted crane
}

\author{
Han Guang-dong ${ }^{1}$, a , Zhang Tong ${ }^{1}$, Chen Haiquan ${ }^{1}$, Zhang Jinnan ${ }^{1}$, Sheng-hai ${ }^{1}$ and DUAN Wen-qi ${ }^{1}$ \\ ${ }^{1}$ College of Marine Engineering, Dalian Maritime University, Dalian 116026, Liaoning, China
}

\begin{abstract}
To suppress the swing of the payload, a kind of sling tray anti-swing device was designed, which reduced the length of the lifting rope to reduce the swing of payload. The kinematic equations of the payload were established under the condition of whether anti-swing device was provided, and the dynamic was carried out in Mat lab/Simulink environment. The swing of the payload under different rolling angles was analysed in a comparative manner. The results showed that the in-plane angle reduced $60 \%$ and out -plane angle reduced $55 \%$ of the payload in the case of the anti-swing device. The simulation results verified the effectiveness of the sling tray anti-swing device.
\end{abstract}

\section{INTRODUCTION}

Ship-mounted cranes are commonly used in cargo handling, offshore installation and replenishment at sea. However, the ship and payload was swing due to the motion of wave. The swing of payload is unavoidable and may put relevant operations in danger.

There are some methods to restrain payload swing of ship-mounted crane. The kinematics model of payload system is established to study the swing of the payload. It is very important for safe and efficient operation of ship-mounted crane [1]. There are two commonly used methods to study the dynamics of the ship-mounted crane: one is to simplify the effect of the hull on payload to the hanging point of lifting arm [2-4]. The results show that the planar motion of hanging point also make the payload to swing in the space [5-6]. The other one is the ship motion and the swing of payload coupling analysis and develop the multi-body dynamics model [7-9]. JANG built dynamic model of ship-mounted container crane [10], and designed a T-S fuzzy controller to reduce the payload swing. ISMAIL built the three-dimensional model of offshore boom crane [11], designed a second order sliding mode controller which could track to expect trajectory while reducing the payload swing. In addition, the mechanical shock was reduced as well. FANG designed a nonlinear controller based on the dynamic model of offshore boom crane [12], and applied Lyapunov method to prove its stability, and finally carried out experiment to testify its performance. WANG Yang conduct the analysis of the motion characteristics of the anti-swing system under rolling condition of crane sling four rope system [13], And put forward the anti-swing device for a rigid rod.

A sling tray mechanical anti-swing system (STMAS) is proposed in paper aiming to reduce the swing of the payload. An anti-swing test bed is designed, analyzed and built to testify the proposed anti-swing system.

${ }^{a}$ Corresponding author : 18842602951@163.com 


\section{KINEMATICS MODEL OF PAYLOAD SYSTEM}

The ship-mounted crane is a mutual coupling rigid body. In addition, the motion of ship-mounted crane is also subject to the interaction of the hull and the wind, wave, flow, with nonlinear characteristics. In paper the ship is looked as an incentive platform, to carry on the roll. The following assumptions are made: the payload could be looked as a point; the quality of rope is negligible and the rope without elastic deformation; the lifting arm of ship-mounted crane as a rigid body without elastic deformation; ship motion in regular wave.

According to these assumptions the kinematics model of the payload system was developed, as shown in Fig. 1.

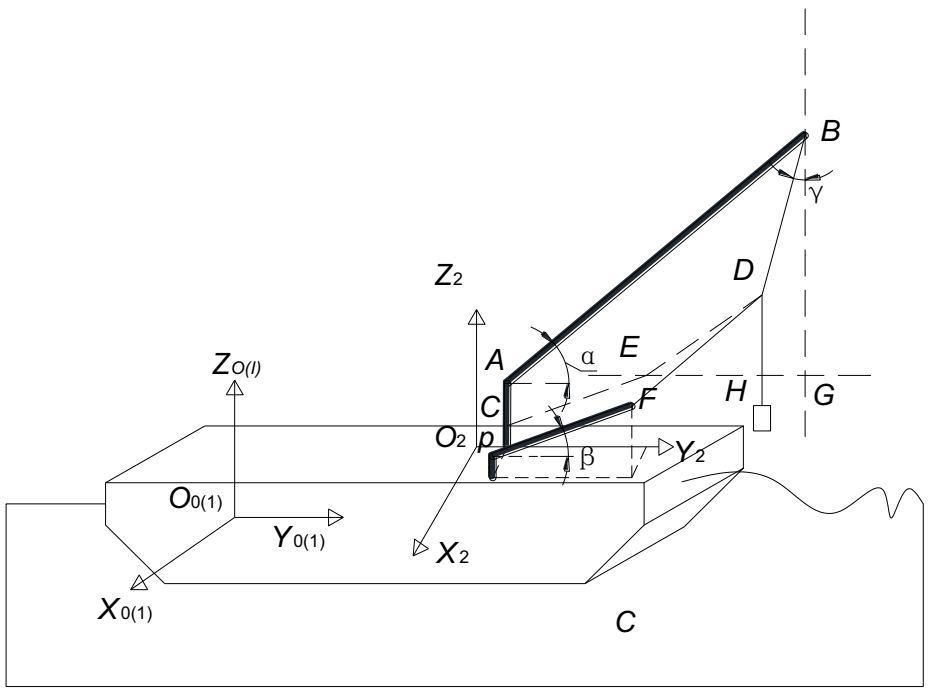

Figure 1. The kinematics model of the payload system

The reference coordinate is defined as follows:

$\left(O_{0}-X_{0} Y_{0} Z_{0}\right)$ as the inertial coordinate system; $\left(O_{1}-X_{1} Y_{1} Z_{1}\right)$ for positioning in the hull on the hull system; $\left(\mathrm{O}_{2}-\mathrm{X}_{2} \mathrm{Y}_{2} \mathrm{Z}_{2}\right)$ is positioning on the base coordinate system origin $\mathrm{O}_{2}$ is the intersection of hull and crane base; the point $p$ is located in the base coordinate system $\left(O_{2}-X_{2} Y_{2} Z_{2}\right)$ with $O_{2} ; \gamma$ is the initial Angle of the lifting rope with the $Z$ axis after put the sling tray mechanical anti-swing system in system.

Through coordinate transform, the coordinate $\left(O_{2}-X_{2} Y_{2} Z_{2}\right)$ could be represented in the hull coordinate system $\left(O_{1}-X_{1} Y_{1} Z_{1}\right)$, transformation relation as follow.

$$
u_{p}=\mathrm{T}_{O_{2}}^{O_{1}} p^{o_{2}}
$$

In Eq. 1 coordinates transform corresponds to the reference coordinate system by superscript and subscript, $u_{p}=\left[\begin{array}{lll}x_{p} & y_{p} z_{p} & 1\end{array}\right]^{\mathrm{T}}$ is the position of $O_{2}$ in the hull coordinate $\left(O_{1}-X_{1} Y_{1} Z_{1}\right)$, and $p^{O 2}=\left[\begin{array}{lll}0 & 0 & 0\end{array}\right]^{\mathrm{T}}$ is the position of crane base original point in base coordinate system, $\mathrm{T}$ is coordinate transform matrix between the base coordinate system $\left(O_{2}-X_{2} Y_{2} Z_{2}\right)$ and the hull coordinate system $\left(O_{1}-X_{1} Y_{1} Z_{1}\right)$.

$$
T_{O_{2}}^{O_{1}}=\left[\begin{array}{cccc}
\cos \alpha & -\sin \alpha & 0 & x_{o_{2}} \\
\sin \alpha & \cos \alpha & 0 & y_{o_{2}} \\
0 & 0 & 1 & z_{o_{2}} \\
0 & 0 & 0 & 1
\end{array}\right]
$$

Because of the motion of the ship, caused the motion of lifting arm but the lifting arm and cargo are connected by wire rope, only three displacements can be transmitted to the payload to cause the swing of the payload, but the attitude movement is not affected. So only need to derive the translational displacements of ship-mounted crane base, the expression as follow. 


$$
u_{o_{2}}=u_{p}+H u_{o_{1}}
$$

Assuming that the ship moving under a regular wave, only considering the ship rolling and pitching, it can be assumed that the motion of the ship as follow.

$$
u_{o_{1}}=\left[\begin{array}{llllll}
0 & 0 & 0 & \eta_{x} & \eta_{y} & 0
\end{array}\right]^{\mathrm{T}}
$$

Without considering the rotation of the crane, the crane as a rigid body, $\alpha=0$, the position of base of crane can be got, $\mathrm{H}$ is the transform matrix.

According Eq.1-Eq.5:

$$
H=\left[\begin{array}{cccccc}
1 & 0 & 0 & 0 & z_{p} & -y_{p} \\
0 & 1 & 0 & -z_{p} & 0 & x_{p} \\
0 & 0 & 1 & y_{p} & -x_{p} & 0
\end{array}\right]
$$

$$
u_{b}=\left(1.5 * \eta_{y},-1.5 * \eta_{y}+3.5,3.5 * \eta_{y}+1.5\right)
$$

The position of point B, E, F can be derived by the coordinates of ub as follows.

$$
\left\{\begin{array}{l}
B\left(x_{b}, y_{b}, z_{b}\right)=\left(\begin{array}{c}
1.5 * \eta_{y} \\
-1.5 * \eta_{x}+4.56 \\
3.5 * \eta_{y}+2.76
\end{array}\right) \\
E\left(x_{e}, y_{e}, z_{e}\right)=\left(\begin{array}{l}
-1.5 * \eta_{y}-0.2 \\
-1.5 * \eta_{x}+3.93 \\
3.5 * \eta_{x}+1.85
\end{array}\right) \\
F\left(x_{f}, y_{f}, z_{f}\right)=\left(\begin{array}{l}
1.5 * \eta_{y}+0.2, \\
-1.5 * \eta_{x}+3.93 \\
3.5 * \eta_{y}+1.85
\end{array}\right)
\end{array}\right.
$$

The force analysis of the sling tray and the payload was carried out by using the method of Descartes.

(1) Statics analysis of the sling tray

The statics analysis in $\mathrm{X}, \mathrm{Y}, \mathrm{Z}$ direction is

$$
\begin{gathered}
F_{1} *\left(\left(x_{f}-x_{d}\right) / l_{d f}+\left(x_{e}-x_{d}\right) / l_{d e}\right)+ \\
F_{2} *\left(\left(x_{h}-x_{d}\right) / l_{d h}+\left(x_{b}-x_{d}\right) / l_{b d}\right)=0 \\
F_{1} *\left(\left(y_{f}-y_{d}\right) / l_{d f}+\left(y_{e}-y_{d}\right) / l_{d e}\right)+ \\
F_{2} *\left(\left(y_{h}-y_{d}\right) / l_{d h}+\left(y_{b}-y_{d}\right) / l_{b d}\right)=0 \\
F_{1} *\left(\left(z_{f}-z_{d}\right) / l_{d f}+\left(z_{e}-z_{d}\right) / l_{d e}\right)+ \\
F_{2} *\left(\left(z_{h}-z_{d}\right) / l_{d h}+\left(z_{b}-z_{d}\right) / l_{b d}\right)=0
\end{gathered}
$$

(2) Kinematics analysis of the payload (With the sling tray)

The statics analysis in $\mathrm{X}, \mathrm{Y}, \mathrm{Z}$ direction is 


$$
\begin{gathered}
m \ddot{x_{h}}=F_{2} *\left(x_{b}-x_{h}\right) / l_{b h} \\
\ddot{m} \ddot{y}_{h}=F_{2} *\left(y_{d}-y_{h}\right) / l_{d h} \\
\dot{m} \ddot{z}_{h}=F_{2} *\left(z_{d}-z_{h}\right) / l_{d h}-m g
\end{gathered}
$$

(3) Kinematics analysis of the payload (Without the sling tray)

The statics analysis in $\mathrm{X}, \mathrm{Y}, \mathrm{Z}$ direction is

$$
\begin{aligned}
& m \ddot{x_{h}}=F_{2} *\left(x_{b}-x_{h}\right) / l_{b h} \\
& m \ddot{y_{h}}=F_{2} *\left(y_{b}-y_{h}\right) / l_{b h} \\
& \dot{m} z_{h}=F_{2} *\left(z_{b}-z_{h}\right) / l_{b h}-m g
\end{aligned}
$$

\section{THE KINEMATICS SIMULATION OF PAYLOAD SYSTEM}

According to the kinematics equations of the payload system, the simulation analysis of the motion of the payload was carried out under the condition of with and without sling tray mechanical anti-swing system in the pitching angles are $5^{\circ}, 9^{\circ}, 13^{\circ}$.

\subsection{The swing of the payload with pitching angle is $5^{\circ}$}
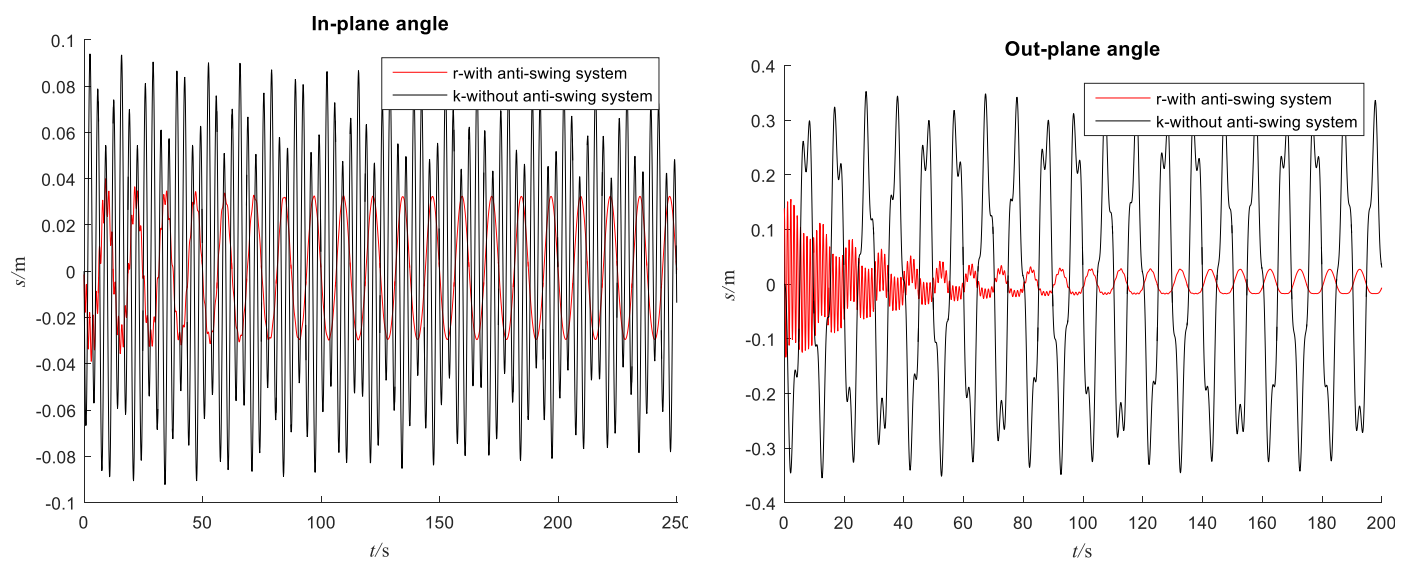

Figure 2 The swing curve of the payload with the pitching angle is $5^{\circ}$

From Fig. 2 can conclude that the ship pitching angle is $5^{\circ}$ without anti-swing system, the maximum in-plane swing of the payload is $0.096 \mathrm{~m}$, the maximum out-plane swing of the payload is $0.36 \mathrm{~m}$. With the anti-swing device, the maximum in-plane swing of the payload is $0.039 \mathrm{~m}$, the range of anti-swing is reduced $59.4 \%$, the maximum out-plane swing of the payload is $0.16 \mathrm{~m}$, the range of anti-swing is $55.6 \%$.

\subsection{The swing of the payload with pitching angle is $9^{\circ}$}



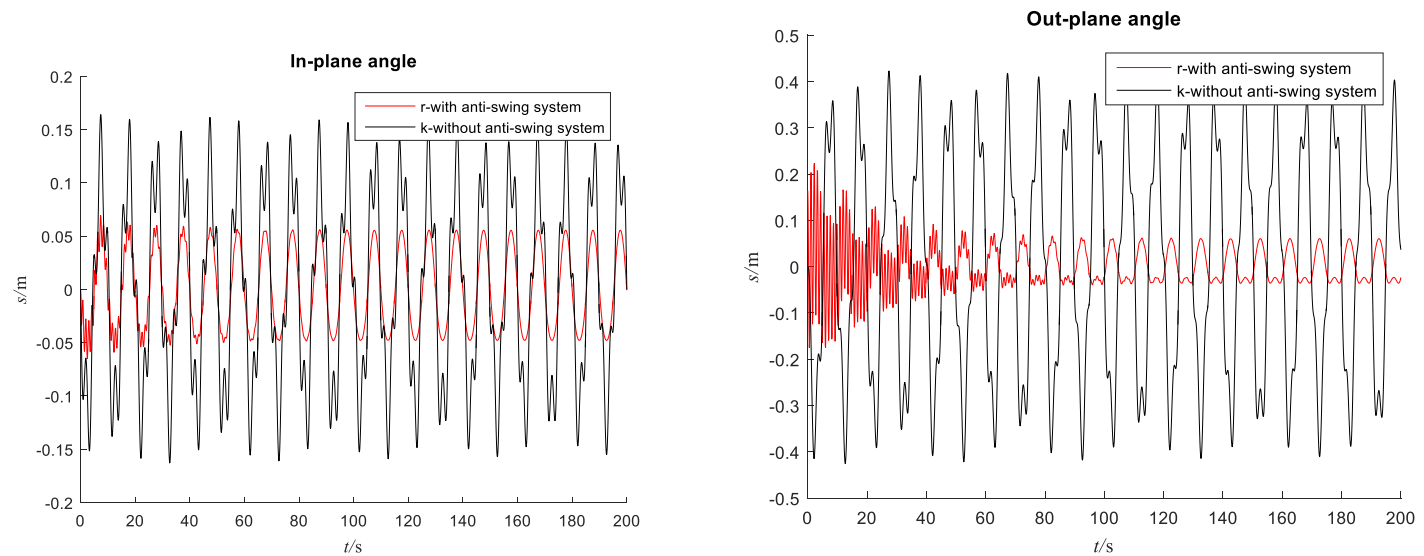

Figure 3 The swing curve of the payload with the pitching angle is $9^{\circ}$

From Fig. 3 can conclude that the ship pitching angle is $9^{\circ}$ without anti-swing system, the maximum in-plane swing of the payload is $0.162 \mathrm{~m}$, the maximum out-plane swing of the payload is $0.44 \mathrm{~m}$. With the anti-swing device, the maximum in-plane swing of the payload is $0.071 \mathrm{~m}$, the range of anti-swing is reduced $56.2 \%$, the maximum out-plane swing of the payload is $0.21 \mathrm{~m}$, the range of anti-swing is $52.3 \%$.

\subsection{The swing of the payload with pitching angle is $13^{\circ}$}
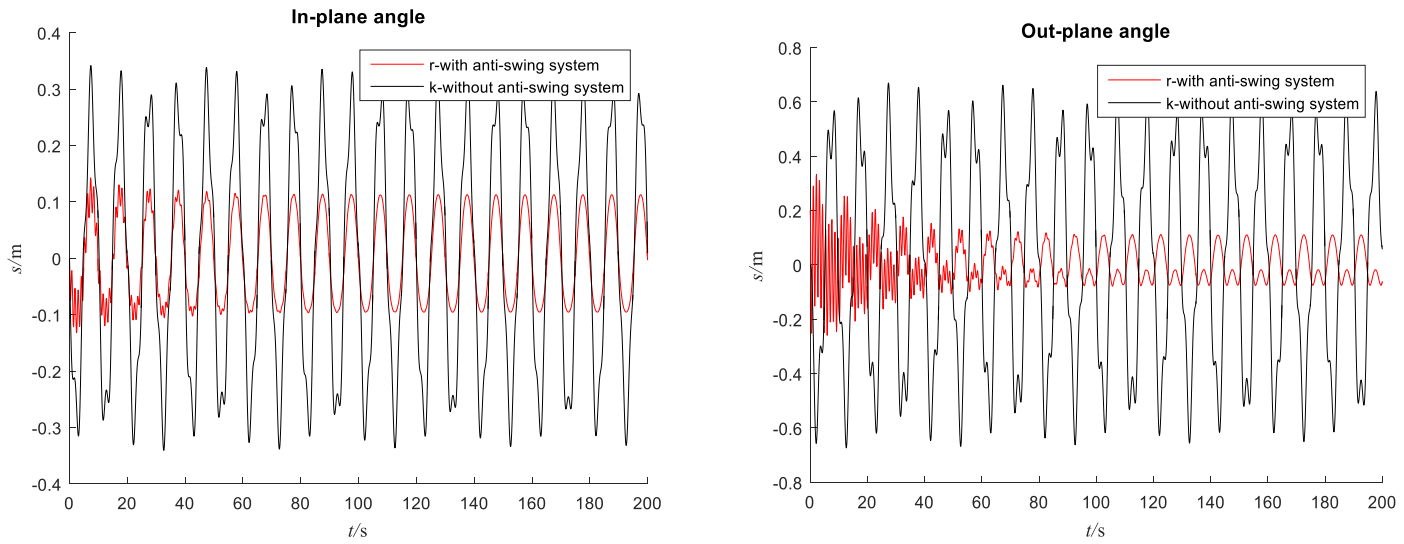

Figure 4 The swing curve of the payload with the pitching angle is $13^{\circ}$

From Fig. 4 can conclude that the ship pitching angle is $13^{\circ}$ without anti-swing system, the maximum in-plane swing of the payload is $0.31 \mathrm{~m}$, the maximum out-plane swing of the payload is $0.68 \mathrm{~m}$. With the anti-swing device, the maximum in-plane swing of the payload is $0.128 \mathrm{~m}$, the range of anti-swing is reduced $58.7 \%$, the maximum out-plane swing of the payload is $0.29 \mathrm{~m}$, the range of anti-swing is $57.4 \%$.

\section{CONCLUSIONS}

The kinematics model of the crane payload system is established and the simulation analysis is obtained using Simulink software with the pitching angles are $6^{\circ}, 11^{\circ}, 16^{\circ}$. According to the results, the sling tray mechanical anti-swing system can reduce the swing amplitude of the payload about $55 \%$. The effectiveness of the sling tray mechanical anti-swing system is verified, it has a certain significance to improve the safety and efficiency of ship crane. 


\section{ACKNOWLEDGMENTS}

The project supported by the Special funds for basic scientific research business of the Central University (3132016345,3132016356); Liaoning Natural Science Foundation of China (2015020132).

\section{References}

1. Wang Xuelin, You Xinyi, Hu Yujin. J. China. M. E. 9, 1077-1082(2010).

2. Henry, R.J, Masoud, Z.N, Nayfeh, A.H, et al. J. V.C, 7, 53-1264(2001).

3. Chin, C, Nayfeh, A.H, Abedl-rahman, E. J. V.C, 7, 199-220(2001).

4. Chin, C.M, Nayfeh, A.H. J. V.C, 7, 891-904 (2001).

5. Ellermann, K, Kreuzer, E, Markiewicz, M. J. Mul. Sys. Dyna. 9, 377-387(2003).

6. Park, KP, Cha, JR, Lee, KY, et al. J. Trans. Korean. S. M.E. 35,15-120(2011)

7. Miles, J.W, J A. S. A. 20,21-32(1962).

8. Miles, J.W, J. Phys. D. Nonl. Phe. 11, 309-323(1984).

9. Patel M, Brown D, Witz J.A. J. Trans. R. I. Nav. Archi. 129, 103-113(1987).

10. J.J Hoon, K. Sung-Ha. \& J.E Tae. J. Cent. South Univ, 19, 163-167(2012).

11. R. M. T. Raja Ismail, Q. P. IEEE International Conference on Automation Science and Engineering (CASE). 17, 996-1001(2013).

12. Fang Yongchun, Wang Pengcheng, Sun Ning, et al. IEEE Transactions on Industrial Electronics, 61,414-427(2014).

13. Yang Wang, J. China. S. S.T, 35, 105-108 (2013) 